\title{
2010s-05 \\ Incentive-Compatible Adjustments from the Anchor and Correlated Equilibrium
}

\author{
Arnaud Z. Dragicevic
}

\begin{tabular}{c}
\hline Série Scientifique \\
Scientific Series
\end{tabular}

\section{Montréal}

Janvier 2010

(C) 2010 Arnaud Z. Dragicevic. Tous droits réservés. All rights reserved. Reproduction partielle permise avec citation du document source, incluant la notice $($ C.

Short sections may be quoted without explicit permission, if full credit, including (C) notice, is given to the source.
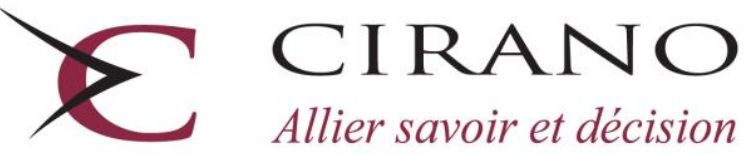

Allier savoir et décision

Centre interuniversitaire de recherche en analyse des organisations 


\section{CIRANO}

Le CIRANO est un organisme sans but lucratif constitué en vertu de la Loi des compagnies du Québec. Le financement de son infrastructure et de ses activités de recherche provient des cotisations de ses organisations-membres, d'une subvention d'infrastructure du Ministère du Développement économique et régional et de la Recherche, de même que des subventions et mandats obtenus par ses équipes de recherche.

CIRANO is a private non-profit organization incorporated under the Québec Companies Act. Its infrastructure and research activities are funded through fees paid by member organizations, an infrastructure grant from the Ministère du Développement économique et régional et de la Recherche, and grants and research mandates obtained by its research teams.

\section{Les partenaires du CIRANO}

Partenaire majeur

Ministère du Développement économique, de l'Innovation et de l'Exportation

\section{Partenaires corporatifs}

Banque de développement du Canada

Banque du Canada

Banque Laurentienne du Canada

Banque Nationale du Canada

Banque Royale du Canada

Banque Scotia

Bell Canada

BMO Groupe financier

Caisse de dépôt et placement du Québec

Fédération des caisses Desjardins du Québec

Financière Sun Life, Québec

Gaz Métro

Hydro-Québec

Industrie Canada

Investissements PSP

Ministère des Finances du Québec

Power Corporation du Canada

Raymond Chabot Grant Thornton

Rio Tinto

State Street Global Advisors

Transat A.T.

Ville de Montréal

\section{Partenaires universitaires}

École Polytechnique de Montréal

HEC Montréal

McGill University

Université Concordia

Université de Montréal

Université de Sherbrooke

Université du Québec

Université du Québec à Montréal

Université Laval

Le CIRANO collabore avec de nombreux centres et chaires de recherche universitaires dont on peut consulter la liste sur son site web.

Les cahiers de la série scientifique (CS) visent à rendre accessibles des résultats de recherche effectuée au CIRANO afin de susciter échanges et commentaires. Ces cahiers sont écrits dans le style des publications scientifiques. Les idées et les opinions émises sont sous l'unique responsabilité des auteurs et ne représentent pas nécessairement les positions du CIRANO ou de ses partenaires.

This paper presents research carried out at CIRANO and aims at encouraging discussion and comment. The observations and viewpoints expressed are the sole responsibility of the authors. They do not necessarily represent positions of CIRANO or its partners. 


\title{
Incentive-Compatible Adjustments from the Anchor and Correlated Equilibrium
}

\author{
Arnaud Z. Dragicevic ${ }^{*}$
}

\begin{abstract}
Résumé / Abstract
En présence de mécanismes de marché répétés avec prix de compensation endogènes, c'est-àdire lorsque les prix dépendent des offres soumises, l'hypothèse de l'indépendance des valeurs privées - sous-jacente à la compatibilité avec les incitations - est remise en question ; même si ce type de mécanismes fournit une participation active et un apprentissage du marché. Dans sa vision orthodoxe, un comportement marchand d'adaptation met en péril la compatibilité avec les incitations. Lorsque les enchérisseurs opèrent dans un équilibre corrélé, nous montrons que les contraintes de compatibilité avec les incitations de même que les signaux publics issus des autres offres sont prises en compte. De manière à maximiser leur profit espéré, les agents à rationalité limitée s'ajustent depuis leur ancrage dans le sens du dernier prix signalé. Ils licitent avec sincérité tant que l'ajustement s'effectue d'après la pondération mémorielle limitée.
\end{abstract}

Mots clés : enchères, compatibilité avec les incitations, dépendance de rang, point de référence, heuristique, rationalité limitée, équilibre corrélé

In repeated-round auction mechanisms with endogenous market-clearing prices, i.e. when prices depend on submitted bids, the assumption of independent private values that underlines the property of incentive-compatibility is to be brought into question; even if these mechanisms provide active involvement and market learning. In its orthodox view, adaptive bidding behavior imperils incentive-compatibility. When agents operate in a correlated equilibrium, we show that neither the incentive-compatibility constraints nor the public signals issued from others' bids are ignored. In order to maximize their expected payoffs, boundedly rational agents adjust from their anchor in the direction of the last posted price. They bid sincerely as long as the adjustment is made pursuant to the bounded memory weighting

Keywords: auctions; incentive-compatibility; correlated equilibrium; anchoring-and-adjustment heuristic; rank-dependence; bounded rationality

Codes JEL : C73, D44, D81, D83

\footnotetext{
* CIRANO and École Polytechnique ParisTech. CIRANO, 2020 rue University, Montréal (QC) H3A 2A5 Canada, arnaud.dragicevic@cirano.qc.ca.
} 


\section{INTRODUCTION}

To know how much an agent is willing to pay for some item, and more generally to assess how agents behave, economists learn from experiments of repeated-round auctions. One of the arguments supportive of repeating auctioning is that practice allows agents to learn about the auction format and form values in a market-like setting, which in turn improves the accuracy of their estimates (Hayes et al. 1995, Lusk et al. 2001, Alfnes and Rickertsen 2003). Discovered preference hypothesis (Plott 1996) says that preferences converge to the same underlying preferences - which are respectful of the expected utility - regardless of the market mechanism. These underlying preferences are discovered after agents repeatedly take decisions, receive feedback on the outcomes of their decisions, and are given incentives to discover which actions best satisfy their preferences. Anomalies to standard theoretical requirements are the results of agents' irrational behaviors, so only later experimental market trials reveal their true preferences.

In auctioning, experimentalists want to learn from truthful agents. To have them sincere, they use the incentive-compatibility constraints, where truthfully stating private information is an optimal strategy for all agents participating in the auction mechanism. Incentive-compatibility is dependent on the assumption that agents have independent values. Although different types of agents select from a menu of strategies under incomplete information, incentive-compatibility forbids the possibility that a given type of agent adjusts her bids to others. However, List and Shogren (1999) unearth affiliation between naïve agents for new goods and influence of posted prices. Bernard (2005) uncovers affiliation but also loss of the bidders' initial values. Other studies find that the price information alters the subjects' valuation (Cox and Grether 1996, Shogren and Hays 1997, Cubitt et al. 2001. Corrigan and Rousu (2006) show by experimentation that posted prices have a statistically significant impact on bids submitted in subsequent rounds. 
The authors make a distinction between bid affiliation and value affiliation, and prefer the bid affiliation as a broader concept; experimentalists observing revealed preferences such as bids, bids' affiliation is more relevant. Finally, Knetsch et al. (2001) report experimental results which imply that bids are influenced by observations of past prices and by expectations of future prices. They argue that the provision of price information induces cross-subject contamination. Although it can simply prove interaction between the learning processes of different subjects, it can most likely be the result of imitation. This is all the more unsurprising since, unlike bargaining, posted prices are the norm (Hanemann 1994).

In auctioning, values are drawn from an affiliated distribution when the publicly posted market-clearing prices - which signal the relative value of the good - shift the bids' distribution. In this paper, we relax the assumption of private values' independence in the repeated-round mechanisms with exogenous and endogenous market-clearing prices, respectively BDM (BeckerDeGroot-Marschak) and NPA (random $n$ th-price auction), when prices are made public at the end of each round. BDM provides poor market learning, the price being determined separately from the bids. As such, bidders have no opportunity to perform in competition that imposes discipline on their behavior (Bohm et al. 1997); ergo market anomalies and violations of economic theory are fostered (Lusk and Shogren 2007). Yet, only a default of interaction makes the independence of bids certain, as the probability of winning of one agent does not depend on the others' preferences. On the contrary, under NPA, the distribution of prices depends on what the opponents are ready to pay or receive for the good. The $n$th highest bid will be linked to the unknown highest value, hence the agent has to assess her opponents and their expected valuations for the good. Although the randomness of the market-clearing price prevents agents from fixing on a stable cost (Shogren et al. 2001), they are counter-incited to chase other bidders' true valuations, which in turn jeopardizes the property of incentive-compatibility. 
We prove that when agents play in correlated strategies they neither ignore the incentivecompatibility constraints nor reject the posted prices issued from others' bids. It implies that adjusting the bids to the posted prices increases their expected payoffs (given the other players) without endangering their truthful bidding. This is our first result. We then employ a behavioral approach and show that agents bid according to the anchoring-and-adjustment heuristic. Bidders weight serial public signals and adjust from their discovered value using posted prices encoded in a bounded memory weighting, that is, they mainly recall the last posted price and their anchor (discovered value). This is our second result. Using the anchoring-and-adjustment heuristic in time-series forecasting is not new. What is new, on the other hand, is the recourse to anchoring to defend truthful bidding. Indeed, why reprehend the adjustment from the anchor if it expresses heavy reliance on the freshly discovered preferences? The general hypothesis is that the selection among strategies is adaptive, in that a decision maker will choose strategies that are efficient in terms of effort and accuracy. Agents are cognitive misers: they tend to choose in the simplest way possible (Hanemann 1994). Of particular interest is that under time constraints, heuristics can be more accurate than a normative procedure such as expected value maximization (Payne et al. 1988). Even if our modus operandi confirms that agents are sincere, it also reveals that auctioneers are boundedly rational utility maximizers.

The paper is organized as follows. Section 2 clarifies what asocial incentive-compatibility is. Section 3 incorporates the incentive-compatibility constraints within strategic interactions and the public signals' reception within the correlated equilibrium. Section 4 presents the behavioral adjustment from the anchor based upon a memory weighting register. Section 5 examines the empirical validity of such a process. Section 6 concludes. 


\section{ASOCIAL INCENTIVE-COMPATIBILITY}

An agent faces a payoff rule where $v_{i}-p\left(p-c_{i}\right)$ if $p<b_{i}\left(p>c_{i}\right)$ and 0 otherwise, with $v_{i}$ being agent $i$ 's value, $b_{i}\left(c_{i}\right)$ her bid (offer) and $p$ the market price issued either from the bids (offers) or from an exogenous price list. An auction is incentive-compatible when $b_{i}=v_{i}\left(v_{i}=c_{i}\right)$ maximizes the agent's expected utility payoff. BDM and NPA are theoretically proved to be incentive-compatible (Kahneman et al. 1990, Shogren et al. 2001). When an agent $i$ bids, she is ignorant of the clearing price. She thus draws its estimate from the probability density function $f_{i}(p)$ with support $[\underline{p}, \bar{p}]$ and the cumulative distribution function $F_{i}(p)$, where $b_{i} \in[\underline{p}, \bar{p}]$. A rational agent submits a bid that maximizes her expected utility payoff, which is twice continuously differentiable and increasing ${ }^{1}$

$$
E\left(u_{i}\right)=\int_{\underline{p}}^{b_{i}} u_{i}\left(v_{i}-p\right) d F_{i}(p)+\int_{b_{i}}^{\bar{p}} u_{i}(0) d F_{i}(p)=\int_{\underline{p}}^{b_{i}} u_{i}\left(v_{i}-p\right) f_{i}(p) d p+\int_{b_{i}}^{\bar{p}} u_{i}(0) d p,
$$

The first integral describes the payoff for random prices below her bid (where she expects a positive surplus). The second integral describes the payoff for random prices between her bid and the maximum possible bid (where she expects a loss). An opposite rule works for offerers. The maximum over $b_{i}$ occurs when $E^{\prime}\left(u_{i}\right)$ with respect to $b_{i}$ is null or

$$
\partial E\left(u_{i}\right) / \partial b_{i}=u_{i}\left(v_{i}-b_{i}\right) f_{i}\left(b_{i}\right)=0,
$$

\footnotetext{
${ }^{1}$ Assumptions that satisfy the von Neumann-Morgenstern utility function.
} 
If the agent bids her value, the probability distribution that her bid equals the price is strictly positive. Given that the maximization is independent of the other agents' bids, we name this outcome the asocial incentive compatibility. For a uniform distribution of values, the incentive to bid their true value is identical for both high and low-type agents in both BDM and NPA (Lusk et al. 2007). In other words, the cost of deviating from truthful preferences has equivalent effects in both auction mechanisms. Nonetheless, the risk of deviating from truthful bidding is unavoidable when the clearing price is issued from others' preferences. Also, it is tricky to distinguish between refining and imitating, not only for experimentalists but for the agents themselves.

\section{SOCIAL INCENTIVE-COMPATIBILITY}

Standard game theory models prescribe dominant strategies. Incentive-compatibility requires that truth telling is best averaged over the types of agents. Each agent has beliefs about the types of other agents (how others value the good) which are independent rational expectations, so the bidding strategies are constrained not to evolve.

Consider an agent $i$ with a value $v_{i}$. Her beliefs on other agents' types are independent of

others' distribution of beliefs. Let $\phi_{i}^{*}$ denote the Nash equilibrium pure strategies. The auction mechanism specifies the probability $f_{i}\left(b_{i}\right)$ that the good is carried by agent $i$ at price $p_{i}\left(b_{i}\right)$. The rationality constraint says that the agent's expected utility payoff function must verify

$$
u_{i}\left(\phi_{-i}, \phi_{i}^{*}\right):=v_{i} f_{i}\left(b_{-i}, b_{i}\right)-p_{i}\left(b_{-i}, b_{i}\right) \geq 0
$$


where $\left(\phi_{-i}, \phi_{i}^{*}\right)$ denotes the pure strategy profile given some strategy of other agents $\phi_{-i}$. The constraint ensures that the agent participates in the auction in case of nonnegative payoffs. Likewise, the incentive-compatibility constraint is such that for each deviation $\delta_{i}^{\prime}\left(\phi_{i}^{*}\right)$ or $b_{i}^{\prime}$

$$
u_{i}\left(\phi_{-i}, \delta_{i}\left(\phi_{i}^{*}\right)\right) \geq u_{i}\left(\phi_{-i}, \delta_{i}^{\prime}\left(\phi_{i}^{*}\right)\right):=v_{i} f_{i}\left(b_{-i}, b_{i}\right)-p_{i}\left(b_{-i}, b_{i}\right) \geq v_{i} f_{i}\left(b_{-i}, b_{i}^{\prime}\right)-p_{i}\left(b_{-i}, b_{i}^{\prime}\right)
$$

The left-hand side of the constraint is the expected utility payoff if the agent reports her true bid $b_{i}$, and the right-hand side of this constraint is the expected utility payoff if she deviates to $b_{i}^{\prime}$. When she bids $b_{i}^{\prime}$, her expected payoff changes but the probability distribution over $b_{-i}$ does not, for she cannot control $b_{-i}$. Henceforth, she affects her expected utility payoff. This constraint asserts that her expected utility payoff from honesty is not less than her expected utility payoff from deviating, i.e. by deviating she can lose. It ensures that the Bayesian Nash equilibrium for all agents is to announce the truth.

If we assume that the agents' types are unknown, a huge computation requirement comes out. Each agent must know the distribution of types of all other agents as well as their ability to determine Nash strategies. In reality, equilibrium computation is infeasible. The distribution over the possible types in repeated-round auctions is so complex that it makes the space of types go off hand. One could eventually calculate the equilibrium, but the absence of common knowledge of type space and prior beliefs make it unlikely (Saran and Serrano 2007). As a consequence, it is realistic to stress that agents observe how others value the good, and some kind of equilibrium emerges (Boutilier et al. 2000).

When the agent's valuation depends on both her information and others' information, private signals are likely to mix: a phenomenon known as affiliated values pioneered by Milgrom 
and Weber (1982). Agents combine their own signal with the signals received from others, which creates affiliation of values (Klemperer 1999). In our case, it means that $b_{i}^{\prime} \rightarrow b_{-i}$ in $v_{i} f_{i}\left(b_{-i}, b_{i}^{\prime}\right)$. Thereby, if a signal from an agent is a high-type, this will increase the probability that other agents have high types as well. As a consequence, a higher value for one agent makes higher values for other agents more likely (Kagel 1995); the agent tends to submit higher bids afterwards (Fox et al. 1998, Cummings and Taylor 1999, List 2001). Indeed, it is hard to believe that the agent assigns an independent value to the good after market information has been revealed. Such a basic agent is insensitive to interactive implications. When the agent is told the market-clearing price, she mostly extracts information on value from it, and price posting makes her update her value without fear of deviation. In case of endogenous market-clearing prices, the agent forms beliefs on the unknown distribution of bids according to others' preferences. Even if signals are irrelevant to the payoffs, they can find themselves into the equilibrium, which suggests existence of a correlated equilibrium (Aumann 1974). Moreover, Bayesian rational agents play a correlated equilibrium as long the Harsanyi common prior assumption is verified (Aumann 1987) ${ }^{2}$.

Following Myerson (1983), suppose a standard game with correlated equilibrium. With the signaling from a trusted third party, i.e. a rightful auction mechanism that communicates endogenous market-clearing prices, there is a recommended strategy from public signaling that generates higher expected utility payoffs. Consider the following expected utility payoff matrix.

\footnotetext{
${ }^{2}$ Common prior only requires the bidders' mutual beliefs on the fundamentals of the interaction be elicited, like expected utility payoffs entailed by the possible actions.
} 


\begin{tabular}{lr|cc|}
\multicolumn{1}{c}{} & \multicolumn{2}{c}{ Agent 2 } \\
& & fixes & adjusts \\
\cline { 3 - 4 } & fixes & $v_{1}^{f}, v_{2}^{f}$ & $v_{1}^{f}, v_{2}^{a}$ \\
Agent 1 & adjusts & $v_{1}^{a}, v_{2}^{f}$ & 0,0 \\
\cline { 3 - 4 } & & &
\end{tabular}

Agents expect some payoff from fixing $\left(v_{i}^{f}\right)$ or from adjusting $\left(v_{i}^{a}\right)$ their true value after they discovered it. Agents learn their private recommended strategy from publicly posted prices. The posted price randomly recommends strategies $\langle\cdot\rangle$ in a way that each pair $\left(v_{1}^{f}, v_{2}^{f}\right),\left(v_{1}^{a}, v_{2}^{f}\right)$ or $\left(v_{1}^{f}, v_{2}^{a}\right)$ is recommended with probability $1 / 3$. There is a Nash equilibrium in this game in which both agents comply with their recommendations.

If agent 1 discerns the recommendation $\left\langle v_{1}^{f}\right\rangle$ from the posted price, she states that agent 2 has been equiprobably recommended $v_{2}^{f}$ or $v_{2}^{a}$ in which case all her responses yield the same expected payoff. If agent 1 discerns $\left\langle v_{1}^{a}\right\rangle$ from the posted price, agent 2 plays $v_{2}^{f}$ to which she best responds by $v_{1}^{a}$. Agent 1 complies with the posted price if agent 2 does alike. Both agents conform to the posted price, which equiprobably randomizes between $\left(v_{1}^{f}, v_{2}^{f}\right),\left(v_{1}^{a}, v_{2}^{f}\right)$ and $\left(v_{1}^{f}, v_{2}^{a}\right)$ and gives the expected payoff allocation of $(1 / 3)\left(v_{1}^{f}, v_{2}^{f}\right)+(1 / 3)\left(v_{1}^{a}, v_{2}^{f}\right)+(1 / 3)\left(v_{1}^{a}, v_{2}^{a}\right)$.

Recommendations are issued from the probability distribution $f_{\rho}$ in $\Delta(\Phi)$ which sets probability distributions over the set of pure strategies $\Phi . f(\phi)$ is the probability that a posted price recommends the pure strategy profile $\phi=\left(\phi_{i}\right)_{i \in N}$, where $N$ is the set of agents. When agents follow their private recommendations, the expected utility payoff under a correlated strategy $f_{\rho}$ 
is $u_{i}\left(f_{\rho}\right)$. There is an incentive-compatible equilibrium when truthful agents conform to their recommendations if and only if

$$
\begin{gathered}
u_{i}\left(f_{\rho} \mid t_{i}\right) \geq \sum_{t \in T} \sum_{\phi \in \Phi} f_{\rho}\left(\phi^{\prime}\right) u_{i}\left(\phi_{-i}, \delta_{i}\left(\phi_{i}\right) \mid t_{i}\right):= \\
v_{i} f_{p}\left(b_{-i}^{\circ}, b_{i}^{\circ}\right)-p_{i}\left(b_{-i}^{\circ}, b_{i}^{\circ}\right) \geq v_{i} f_{p}\left(b_{-i}^{\circ}, b_{i}^{\prime}\right)-p_{i}\left(b_{-i}^{\circ}, b_{i}^{\prime}\right),
\end{gathered}
$$

where $\phi=\left(\phi_{-i}, \phi_{i}\right), \forall i \in N, \forall t_{i} \in T, \forall \delta_{i}: \phi_{i} \rightarrow \phi_{i}$. If all other agents play their recommended actions according to their own types $\phi_{-i}$ ( or $b_{-i}^{\circ}$ ), agent $i$ 's expected utility payoff $u_{i}$ from playing her type $t_{i} \in T$ while following her private recommendation is not less than her utility from playing an action $\phi^{\prime}$ as if she were of some other type. Thus, $b_{i}^{\circ}$ is the bid which comes out from the public signal given the agent's true value and $b_{i}^{\prime}$ encapsulates some deviant action. The recommendation is the best in expectation so rational agents comply with it. The expression satisfies the conditional independence property (Forges 1993) necessary in settings of incomplete information, given that $\delta_{i}\left(\phi_{i}\right)$ is conditionally independent of $t_{-i}$.

An additional probability constraint is added

$$
\sum_{\phi^{\prime} \in \Phi} f_{\rho}(\phi \mid t)=1, \text { and } f_{\rho}\left(\phi^{\prime} \mid t\right) \geq 0, \forall \phi^{\prime} \in \Phi, \forall t \in T
$$

The probability constraint is the conditional probability of the recommended action $\phi$ if each player reports her type and $\phi: T \rightarrow \Delta(\Phi)$. The correlated equilibrium which maximizes the agents' expected utility payoffs is $f_{\rho}\left(v_{1}^{f}, v_{2}^{f}\right)=f_{\rho}\left(v_{1}^{a}, v_{2}^{f}\right)=f_{\rho}\left(v_{1}^{f}, v_{2}^{a}\right)=1 / 3$ and $f_{\rho}\left(v_{1}^{a}, v_{2}^{a}\right)=0$. The public signal equals a correlated equilibrium if [5] and [6] are satisfied. The single-way 
message from a posted price to the agents guarantees asocial valuation which in turn ensures truthful bidding.

Proposition 1. When true-type agents follow public signals recommended from endogenous market-clearing prices, they operate in a correlated equilibrium.

Proof in Appendix A.

The correlated equilibrium has the advantage of being reasonable, simple and is guaranteed always to exist. The rationality constraint says that an agent has no reason to bid in case of null payoff. Since losing in auctioning means absence of payoff, increasing the expectation of winning the auction and consequently the chance of earning some positive payoff by adjusting her true value seems quite rational. In parallel, a rational agent seeks to maximize her expected payoff which is the difference between her value and the final cost of the item. If by adjusting her true value, an agent increases her expected utility payoff, she seems to act rationally quite as much.

Altogether, correlated strategies $f_{\rho}$ induce a game in which each agent selects her action as a function of the price public signaling. This action cannot depend on others' types as the recommendation is fully private. This ensures that the auction mechanism is incentivecompatible. Still, how can one distinguish true from fallacious type when agents incorporate endogenous public signals into their strategies? The next section answers this question.

\section{ANCHORING-AND-ADJUSTMENT}


We state that agents start with their anchors and incorporate serial weighted public signals into their bidding strategies. We know that agents use the distribution of posted prices they've observed at earlier rounds to update their bidding policy and their estimate of the distribution of bids. Their bidding strategy in the next round is based on the updated distributions and all agents play a Nash equilibrium in a Bayesian manner. If the agent updates her bidding policy based on past observations, her bids or offers at early rounds are not reflective of her bids or offers at latter rounds, which means that she learns based on observations drawn from a nonstationary distribution. It has been shown that myopic learning models such as fictitious play - which is an adaptive heuristic - converge to a stationary distribution despite the initial nonstationarity (Fudenberg and Levine 1998). In a fictitious play, the agent is enabled to learn if she can realistically win the auction given her true value. She learns by observing the history of past bids or offers - prior to the beginning of the next round - and forms a belief about her opponents' bids or offers in the next period. She believes that her opponents are using a stationary strategy which is the empirical distribution of past bids or offers, and thus updates her beliefs and her best reply based on earlier outcomes, which defies the statement of truth-telling.

In settings where agents repeatedly interact, an adaptive heuristic is a rule of behavior. Anchoring-and-adjustment is a heuristic employed to assess probabilities. Agents start with an anchor and make adjustments to reach their estimate ${ }^{3}$ (Slovic and Lichtenstein 1971, Tversky and Kahneman 1974). For example, agents use this heuristic to forecast business and financial targets (Bromiley 1987, Russo and Schoemaker 1989, Andreassen and Kraus 1990, Lawrence and O'Connor 1992). They form an estimate of the trustworthiness of the anchor and the data at hand

${ }^{3}$ Einhorn and Hogarth (1985) have also considered the anchoring-and-adjustment process to describe how people make judgements under ambiguity; their adjustment is made according to some probability $p$ which could come from any distribution. 
(Gigerenzer et al. 1991). The adjustments from the anchor are meant to increase their expected utility payoffs. Arkes et al. (2008) term the adaptation of the reference point $r_{k}$ the rule where bidders shift their reference point in the direction of a realized outcome. An agent makes her bid in $k+1$ round, with $k=1, \ldots, n$. Depending on whether the price $p_{k}>r_{k-1}$ or $p_{k}<r_{k-1}$, she scales her bid up and down, respectively. If the price is higher than her anchor, she revises her value and her bid upwards to increase her expected utility payoff, given that she learns that she earns a null payoff with her previous bid: where she does not maximize any utility. If the price is lower than her anchor, she revises her value and her bid downwards in order to augment her expected payoff, as she learns that she can adjust her anchor and take part to the winning trades: where she maximizes her expected payoff plus obtains an additional gain ${ }^{4}$. A rational agent is programmed to maximize her expected payoff, so adjusting cannot be irrational. Besides, we know that strategies based on adaptive heuristics yield boundedly rational strategies in the long run (Hart 2005).

Following adaptation upon sequential stimuli (Hardie et al. 1993) and rank-dependent expected utility (Bleichrodt and Pinto 2000), consider the weighting of serial signals. Linear probability weighting corresponds to standard rationality due to indifference to rank-dependence. We term indifference to rank-dependence unbounded memory weighting. Fictitious play rests upon such a process, for the history of all past actions counts. Conversely, Tversky and Kahneman (1992) consider the weighting function an s-shaped function due to misperceiving of mean probabilities. We term their nonlinear rank-dependence bounded memory weighting.

\footnotetext{
${ }^{4}$ Aumann has argued that rationality should be examined in the context of rules rather than acts, i.e. rules of behavior that are better to other rules.
} 
We then proceed from the idea of s-shaped information weighting developed by Baucells et al. (2010). Agents accumulate ranks to constitute a bidding policy set up on their serial memory ${ }^{5}$. In parallel to probability weighting function (Einhorn and Hogarth 1985, Tversky and Wakker 1995), assume a weighted memory register. The memory register weights the cumulative ranks according to an increasing function $w(\cdot)$, where $w:[0,1] \rightarrow[0,1]$ with $w(0)=0$ and $w(1)=1$. The accumulation departs from the last posted price $(1 / n)$ and ends with the anchor $(n / n)$. Unbounded memory weighting stands for an equal weighting between two rounds ${ }^{6}$. Following Helson's (1964) conceptualization, the bid is formulated as

$$
b_{k}=\gamma(1 / k)\left(b_{1}+\sum_{k=1}^{n} p_{k}\right) \text {, }
$$

where $b_{k}$ is the adjusted bid at rank $k$, given the anchor $b_{1}$, the linear weighting parameter $\gamma$ and the average of past posted prices $\sum_{k=1}^{n} p_{k}$.

The cumulative prospect theory suggests an s-shaped weighting that overweights extreme outcomes which occur with small probabilities and underweights average outcomes which occur with high probabilities. Bounded memory register overweights the anchor $1-w(1-(1 / n))$ and the last posted price $w(1 / n)$ and underweights the prices in-between $w(1-(1 / n))-w(1 / n)$. It is steep near 0 and 1 and mild in-between (Figure 1). This formulation can be related to a bounded fictitious play where the beliefs of an agent depend on the empirical distribution of her

\footnotetext{
${ }^{5}$ Manski (2004) shows that accumulation of empirical evidence over time successively narrows the class of feasible outcome distributions, called the identification region.

6 This approach is different from Forges and Peck (1995) where the information of the agent before making her decision consists of the past aggregated bids.
} 
opponent's most recent actions (Sela and Herreiner 1999). A motivation for bounded recall is the observation that a bounded memory length is optimal if all other agents use the same memory length (Honkapohja and Mitra 2003).

This cognitive process yields the recency and primacy effects, which clarify that best recalls come from the late and early items in a list (Frensch 1994). Numerous examples can be found. Investors partially update their reference point after a stimulus is presented to a price between the purchasing price and the current price (Spranca et al. 1991, Weber and Camerer 1998, Baucells et al. 2010) ${ }^{7}$; Northcraft and Neale (1987) explain that in real estate management, finally agreed prices are significantly affected by the initial bid prices; Hardie et al. (1993) show that consumers give higher weight to recent stimuli than past stimuli; Collins and Barnes (2009) show that recent stimulus history creates a running average of anticipatory timing.

Figure 1: Bounded memory weighting

Figure here

We are now in presence of a three-stage weighting such as

$$
b_{k}=\left(1-\gamma_{h}((n-1) / n) b_{1}+\gamma_{m}((n-2) / n)\left(\sum_{k=1}^{n-1} p_{k}\right)+\left(\gamma_{h}(1 / n)-0\right) p_{n},\right.
$$

\footnotetext{
${ }^{7}$ Other reference point used by individuals is the historical peak (Gneezy 2005) and expectations about future outcomes (Koszegi and Rabin 2006).
} 
where $b_{k}$ is the adjusted bid at rank $k$, given the anchor $b_{1}$ highly weighted by $\gamma_{h}$ at rank $(n-1) / n$, the last posted price $p_{n}$ highly weighted by $\gamma_{h}$ at rank $(1 / n)$, and the average of posted prices in-between $\sum_{k=1}^{n-1} p_{k}$ moderately weighted by $\gamma_{m}$ at rank $(n-2) / n$.

The agent is bidding truthfully if she repeats a sincere bid both in $k+1$ and $k$. In our case, the agent will adjust her bid in the direction of the last posted price. We deal with endogenously cleared posted prices issued from anybody's bid, so linear weighting meant to reveal rationality (Van de Kuilen 2009) no longer holds. Literature states that truth-telling is rational and affiliating private values on public signaling is not. While we consider discovered preferences hypothesis to reveal the agent's anchor, we assert that adjusting the anchor up to the last posted price does not threaten truthful bidding. We know that the adjustment from a precise anchor results in a moderate update (Janiszewski and Uy 2008). In our case, high weighting of the anchor stands for high regard to discovered preferences. Likewise, adjustment means an adaptive rule that maximizes the expected payoff (given the other players), which is the only purpose that matters to rationality. The two suggest that sincere agents are boundedly rational. Once an agent has discovered her preferences, she is considered insincere if she scales her anchor in line with the unbounded memory register, where the sequence of prices drowns her anchor.

Proposition 2. An agent is truth-telling inasmuch as she plays pursuant to the bounded memory weighting, i.e. so long as she behaves as a boundedly rational utility payoff maximizer.

Proof in Appendix B. 
The correlation between private signals comes from the commonly observed history of play and best responses are determined by the history of public signals. If agents confine their adjustment from the anchor to the latest posted price, we consider that they play truthfully. Bounded memory weighting is a way to reflect such a bidding strategy ${ }^{8}$. While agents would be regarded as irrational in the standard literature, we consider sincere bidders boundedly rational.

\section{EMPIRICAL TEST}

Let us now test the empirical relevance of our propositions. We reprocess the home-grown data from the BDM and NPA experiments on carbon offset realized by Dragicevic and Ettinger (2010). In their experiments, agents bought and sold certificates of one ton of carbon offset over ten rounds by means of willingness-to-pay (WTP) and willingness-to-accept (WTA). We decide to analyze the data from the five (out of ten) last rounds because we consider agents to have discovered their preferences after four practice rounds for sure (see Table 1); if agents are to compute their bids or offers from untruthful types, they most likely do it from this point of time. Because market-clearing prices are exogenous under BDM, unbounded memory weighting does not compromise incentive-compatibility. If all posted prices are uniformly weighted, subjects are at worst naïve, for it is irrational to run after luck. The market-clearing price is endogenously chosen under NPA, so the value of the good is worth somebody's value. If every posted price is uniformly weighted, subjects are insincere because they are explicitly copying the others' values.

Table 1: Summary statistics of the unbounded and bounded memory estimates

${ }^{8}$ Contrary to Dasgupta and Maskin (2000) we do not use all available information nor do we assume common value. Besides, our model deals with cumulative ranks. 
Insert Table

According to [7] and [8], we estimate the bids and offers of the subsequent round subject to the unbounded and bounded memory weightings using one-parameter factors from Tversky and Kahneman (1992): $\gamma=1, \gamma_{m}=0.61$ and $\gamma_{h}=0.69$ for the linear, moderate and high weightings. We employ linear $\gamma(1 / n)$ rather than power $(1 / n)^{\gamma}$ factoring, for the anchor gets underweighted otherwise. We normalize the sequential weights to one in order to compute the anchors from which bids and offers are figured out, and compare them to real data (Table 2).

Our first investigation reveals that within BDM, only $26 \%$ of offerers and $22 \%$ of bidders fix their anchor. Within NPA, these figures even collapse to $13 \%$ for both offerers and bidders. The bidding is thus in motion until the last round. To see whether agents base strategies upon the posted prices' adjustment, we study the average adjustment in bids and offers between two rounds. We look at Student's $t$ distribution between experimental and theoretical data and regard whether they fit. With NPA and under both weighting mechanisms, the theoretical adjustments in bids and offers are not significantly different from the real adjustments in bids and offers. The $t$ test fails to reject the null hypothesis that the theoretical adjustments in offers and the real adjustments in offers come from the same distribution at the $p<0.05$ level. With BDM, under both weighting mechanisms, the theoretical adjustments in offers are not significantly different from the real adjustments in offers either. We do not reject the null hypothesis that the theoretical and experimental data are equal at the $5 \%$ level of a $t$-test. On the contrary, the theoretical 
adjustments in bids are significantly different from the real adjustments under both weightings. Here we reject the null hypothesis at the $5 \%$ level of a $t$-test. The estimated distributions do not fit with the real BDM bidding distribution.

Residuals are then compared. In the first place, we examine the average WTA estimates. Under BDM, we notice that the average bounded memory SSE $(6.67 ; 24 \%$ less than one) is lower than the average unbounded memory SSE (12.62; $4 \%$ less than one), showing that the offerers are sincere and weight their anchors heavily. Under NPA, the average bounded memory SSE $(9.33 ; 33 \%$ less than one) is lower than the average unbounded memory SSE $(13.17 ; 30 \%$ less than one), which suggests truthful offering. The values of the two weighting mechanisms are close, which is unsurprising since market prices are issued from the offers. We see that the difference between refining and imitating is thin but real. After that, we observe the average WTP bids. Under BDM, we see that the average bounded memory SSE (5.82; $41 \%$ less than one) is lower than the average unbounded memory SSE (10.61; 30\% less than one), showing that bidders weight their anchors enough to remain sincere. Under NPA, the average bounded memory SSE $(5.65 ; 23 \%$ less than one) is lower than the average unbounded memory SSE $(6.85 ; 18 \%$ less than one), which means truthful bidding. The difference shows that they incorporate posted prices to increase their expected payoff.

We then regress on the anchor and the list of posted prices, which allows us to obtain respective $\gamma$-factors and compare them to those of Tversky and Kahneman. The least squares regression results are presented in Table 2. All estimates are significant, i.e. all $p$-values amount less than 0.001, and all $R$-squares are higher than 0.9. Despite their comparability, each market side has its own factor. We do not identify $\gamma_{m}$ in bounded memory weighting; the factor oscillates around zero and is not significant. 
Table 2: $\gamma$-factors statistics

Insert Table

The average bounded memory weighting from the $\gamma$-factors is illustrated in Figure 2. All the weight is distributed between the anchor and the last posted price, with a massive regard given to the anchor, which proves the agents' sincerity as well as the relevance of our model. We denote that the average SSE is higher on the offerers' side than on the bidders' side. This is due to loss aversion of some agents, who systematically proposed a ceiling WTA. When we ignore them, the average SSE is similar between both market sides.

Figure 2: Average bounded memory weighting

Figure here

We observe an overvaluation of $\gamma$-factors compared to those from Tversky and Kahneman. The overvaluation cannot arise in elicitation procedures which are deficient in social interactions, so this bears quantitative evidence to the effects arisen from the interactions. The average theoretical 
WTP and WTA are beneath the average real bids and offers under both auction mechanisms. Their overstatement could result from the combination of regret and competitive pressure. Disappointment aversion (Horowitz 2006) says that a bidder overbids because she is more disappointed from not receiving the good than from receiving it overpriced. Likewise, WTA posted prices incorporate behavioral effects of loss aversion and disposition (Weber and Camerer 1998), which operate like a catalyst. The likeness of factors suggests a similar magnitude of effects on both market sides.

By means of correlated strategies, we showed that adjusting was impulsed by the pursuit of higher expected payoff (given the other players). Let us verify this. We compare the expected percentage of agents who obtain a positive payoff by fixing their anchor and those who adjust up to the last market-clearing price with real data. The results presented in Table 3 show that adjusting pays, since both expected and real adjusting gainers outnumber.

Table 3: Expected and real gainers from adjustment

Insert Table

Second, we measure up the average expected payoffs with and without adjustment with real payoffs with and without adjustment. The results are presented in Table 4 . We observe that adjusting is in general gainful, for only BDM offerers are penalized for having moved from their anchor; this is unsurprising in view of the fact that the exogenous market-clearing price makes it 
a naïve strategy. Within NPA, adjusting from the discovered value upon the last posted price paid in both expected and real scenarios.

Table 4: Expected and real gains from adjustment

Insert Table

\section{CONCLUSIONS}

The validity of incentives for truthful valuation is questioned whenever an agent's probability of winning depends on the moves of others, such as with the endogenous market-clearing price auctions. Does it imply that the data obtained from experiments with endogenous market-clearing prices are unusable because of the risk of bids' affiliation? It amounts to saying that experimentalists have to choose between the absence of market learning with exogenous marketclearing price auctions and the risk of dependence of private values that exists under NPA.

In repeated-round auctions, the private-value-independence assumption behind incentivecompatibility may be unrealistic and malapropos. When the bids' adjustments get correlated, the observed bid for a good after a round impacts the estimated price of the good at the next round. Agents revise their beliefs to reflect this publicly revealed information. We show that they start their valuation with an intrinsic anchor - their first true reference point - and then adjust this value using public signals encoded in a memory weighting register. Our empirical test confirms the capacity of auction mechanisms to be demand-revealing. Contrary to other studies, our work 
shows that accounting for posted prices without rejecting the incentive-compatibility constraints differentiates sincere from insincere bidding or offering. Incentive-compatibility need not be excluded in presence of adjustment from the anchor, as long as one verifies heavy weighting of the anchor. Ultimately, instead of condemning behaviors that tie in, we believe that the best approach is to investigate conditions under which incentive-compatibility constraints can be maintained. The notion of truth, which is contingent on human perception, convention, and social experience, should be reformulated. We suggest a form of social rationality where the correlated equilibrium plays a key role.

\section{APPENDIX A: PROOF OF PROPOSITION 1}

Suppose an initial reference value $v_{i}(i=1,2)$. The last posted price amounts $p_{i} \equiv v_{i} \pm \varepsilon$. Agent $i$ faces an equiprobable trend of the market value, i.e. bullish $v_{i}+\varepsilon$ or bearish $v_{i}-\varepsilon$. She can adjust her anchor according to the last posted price in the next round. We have two cases. In spite of the posted price, the anchor of agent $i$ is not updated and remains at $v_{i}$. The expected value of payoff is

$$
v_{i}^{f} \equiv(1 / 3)\left[\left(v_{i}-\left(v_{i} \pm \varepsilon\right)+(1 / 2)\left(v_{i}-\varepsilon-v_{i}\right)+(1 / 2)\left(v_{i}+\varepsilon-v_{i}\right)\right]=\mp(1 / 3) \varepsilon\right.
$$

The anchor is updated to $v_{i} \pm \varepsilon$ due to the last posted price. The expected value of payoff is

$$
v_{i}^{a} \equiv(1 / 3)\left[\left(v_{i} \pm \varepsilon\right)-\left(v_{i} \pm \varepsilon\right)+(1 / 2)\left(v_{i}-\varepsilon-\left(v_{i} \pm \varepsilon\right)\right)+(1 / 2)\left(v_{i}+\varepsilon-\left(v_{i} \pm \varepsilon\right)\right)\right]=\mp(1 / 3) \varepsilon .
$$


One can see that $v_{i}^{a} \geq v_{i}^{f}$, which implies an expected payoff from adjusting at least as high as that from fixing the anchor. Now consider the following game payoff matrix. The market-clearing price, which determines the respective payoffs, is endogenous and issued from the bids. Agent $i$ discovers her preferences and thus her expected value of payoff

Agent 2

\begin{tabular}{rr|cc|}
\multicolumn{1}{c}{} & \multicolumn{2}{c}{ fixes } & adjusts \\
\cline { 3 - 4 } Agent 1 & fixes & $\mp(1 / 3) \varepsilon, \mp(1 / 3) \varepsilon$ & $\mp(-1 / 6) \varepsilon, \mp(1 / 6) \varepsilon$ \\
& adjusts & $\mp(1 / 6) \varepsilon, \mp(-1 / 6) \varepsilon$ & 0,0 \\
\cline { 3 - 4 } & &
\end{tabular}

She chooses either to fix the anchor $v_{i}^{f}$ or to adjust from her anchor to the last posted price: $v_{i}^{a}$. An agent who adjusts but hopes that the other agent fixes her anchor expects a positive payoff of $(1 / 2)(\mp \varepsilon)-(1 / 3)(\mp \varepsilon)=\mp(1 / 6) \varepsilon$; conversely, she expects $\mp(-1 / 6) \varepsilon$ if she fixes her anchor while the other agent adjusts. Finally, when bids converge, agents face a null payoff, as it amounts the difference between the private value and the market-clearing price.

The third party sends private recommendations. There is a correlated equilibrium if no agent refuses to follow her recommendation. If the row agent receives the signal "adjust" given she has no chance to win some positive payoff by fixing her anchor, she has no incentive not to follow, because adjusting is better in expectation. The row agent assigns a positive conditional probability of $1 / 2$ to each of the two pairs of signals (fix, adjust) and (adjust, adjust). If the column agent follows the same rule, the (uncorrelated) expected payoff of the mixed strategy equilibrium by fixing and adjusting respectively yields 


$$
\begin{gathered}
(1 / 2)[\mp(1 / 3) \varepsilon, \mp(1 / 3) \varepsilon]+(1 / 2)[\mp(-1 / 6) \varepsilon, \mp(-1 / 6) \varepsilon]=[\mp(1 / 12) \varepsilon, \mp(1 / 12) \varepsilon] . \\
(1 / 2)[\mp(1 / 6) \varepsilon, \mp(1 / 6) \varepsilon]+(1 / 2)[0,0]=[\mp(1 / 12) \varepsilon, \mp(1 / 12) \varepsilon] .
\end{gathered}
$$

Therefore, agent $i$ is at least as good by adjusting, that is, she is better-off by not letting the other agent adjust at her expense. The game being symmetrical, the column agent has no incentive to ignore her recommendation either. Both agents end up adjusting.

An agent never refuses to follow the recommendation in case of increased expected payoff. The correlated equilibrium yields the following expected payoff

$$
(1 / 3)\{[\mp(1 / 3) \varepsilon, \mp(1 / 3) \varepsilon]+[\mp(-1 / 6) \varepsilon, \mp(1 / 6) \varepsilon]+[\mp(1 / 6) \varepsilon, \mp(-1 / 6) \varepsilon]\}=[\mp(1 / 9) \varepsilon, \mp(1 / 9) \varepsilon]
$$

The correlated equilibrium yields probabilities of $1 / 3$ to each combination that yields a positive outcome. The expected payoff amounts to $\mp(1 / 9) \varepsilon$, which dominates the expected payoff of the mixed strategy Nash equilibrium in case of $(+\varepsilon)$ and dominates the expected payoff of the pure strategy of fixing in case of $(-\varepsilon)$. Therefore, agent $i$ takes the price into account, making the bids affiliated.

\section{APPENDIX B: PROOF OF PROPOSITION 2}

ProOf OF Proposition 2. Think of a low-type agent and posted prices issued from high-type agents, such that prices exceed the anchor. Rewriting [7] with $v_{k} \equiv b_{k}\left(=b_{1}\right)$, meaning that the 
value equals the anchor, the unbounded memory weighting yields un update at $k$ round such that $b_{k}=(1 / k) \gamma_{m}\left(b_{1}+\sum_{k=1}^{n} p_{k}\right)$ thus $v_{k}=(1 / k) \gamma_{m} v_{k}+(1 / k) \gamma_{m} \sum_{k=1}^{n} p_{k} \Leftrightarrow v_{k}\left(1-(1 / k) \gamma_{m}\right)$. We have

$$
v_{k}=\frac{(1 / k) \gamma_{m} \sum_{k=1}^{n} p_{k}}{1-(k-1) \gamma_{m}} \text {. }
$$

As $1-(k-1) \gamma_{m} \rightarrow 1, v_{k} \rightarrow(1 / k) \gamma_{m} \sum_{k=1}^{n} p_{k}$, that is, the agent's anchor equals the average of posted prices. This is incompatible with the demand-revealing property, in particular if public signals come from high-type agents.

If we rewrite [8] with $v_{k} \equiv b_{k}\left(=b_{1}\right)$ the bounded memory weighting yields an update of $b_{k}=\left(1-\gamma_{h}((n-1) / n) b_{1}+\gamma_{m}((n-2) / n)\left(\sum_{k=1}^{n-1} p_{k}\right)+\gamma_{h}(1 / n) p_{n}\right.$ which now corresponds to a value $v_{k}$ that amounts $\left(1-\gamma_{h}((n-1) / n)\right) v_{k}+\gamma_{h}(1 / n) p_{n}+\gamma_{m}((n-2) / n)\left(\sum_{k=1}^{n-1} p_{k}\right)$. After we develop and factor, the expression equals $v_{k}-v_{k}\left(1-\gamma_{h}\right)=\gamma_{h}(1 / n)\left(v_{k}+p_{n}\right)+\gamma_{m}((n-2) / n)\left(\sum_{k=1}^{n-1} p_{k}\right)$. Finally, the equation yields $\gamma_{h} v_{k}(1-(1 / n))=\gamma_{h}(1 / n) p_{n}+\gamma_{m}((n-2) / n)\left(\sum_{k=1}^{n-1} p_{k}\right)$ that is,

$$
v_{k}=\frac{\gamma_{h}(1 / n) p_{n}+\gamma_{m}((n-2) / n) \sum_{k=1}^{n-1} p_{k}}{\gamma_{h}(1-(1 / n))}
$$

The anchor's increment $1-(1 / n)$ and its high weighting $\gamma_{h}$ determine the agent's value which is not captured by the sequential market-clearing prices. Regarding our low-type agent that receives a high-type public signal, she remains sincere.

\section{REFERENCES}


Alfnes, F. and Rickertsen, K. (2003), “European Consumers' Willingness to Pay for U.S. Beef in Experimental Auction Markets”, American Journal of Agricultural Economics, 85: 396-405.

Arkes, H., Hirshleifer, D., Jiang, D. and Lim, S. (2008), "Reference Point Adaptation: Tests in the Domain of Security Trading", Organizational Behavior and Human Decision Processes, 105: 67-81.

Andreassen, P. and Kraus, S. (1990), "Judgmental Extrapolation and the Salience of Change", Journal of Forecasting, 9: 347-372.

Aumann, R. (1974): "Subjectivity and Correlation in Randomized Strategies," Journal of Mathematical Economics, 1: 67-96.

Aumann, R. (1987): “Correlated Equilibrium as an Expression of Bayesian Rationality," Econometrica, 55: 1-18.

Baucells, M., Weber, Martin and Welfens, F., (2010), "Reference Point Formation and Updating: Theory and Experiments", Available at SSRN: http://ssrn.com/abstract=1022930

Becker, G., DeGroot, M., and Marschak, J. (1964), "Measuring Utility by a Single Response Sequential Method", Behavioral Science, 9: 226-232.

Bernard, J. (2005), "Evidence of Affiliation of Values in a Repeated Trial Auction Experiment", Applied Economics Letters, 12: 687-691.

Bleichrodt, H. and Pinto, J. (2000), “A Parameter-Free Elicitation of the Probability Weighting Function in Medical Decision Analysis", Management Science, 46: 1485-1496.

Bohm, P., Linden, J. and Sonnegard, J. (1997), "Eliciting Reservation Prices: Becker-DeGrootMarschak Mechanisms vs. Markets", Economic Journal, 107: 1079-1089. 
Bromiley, P. (1987), "Do Forecasts Produced by Organizations Reflect Anchoring and Adjustment", Journal of Forecasting, 6: 201-210.

Boutilier, C., Goldszmidt, M., Monteleoni, C. and Sabata, B. (2000), “Resource Allocation Using Sequential Auctions", LNCS: Agent Mediated Electronic Commerce II, 1788: 131-152.

Cherry, T., Crocker, T. and Shogren, J. (2003), "Rationality Spillovers", Journal of Environmental Economics and Management, 45: 63-84.

Collins, C. and Barnes, G. (2009), "Predicting the Unpredictable: Weighted Averaging of Past Stimulus Timing Facilitates Ocular Pursuit of Randomly Timed Stimuli”, Journal of Neuroscience, 29: 13302-13314.

Corrigan, J. and Rousu, M. (2006), "Posted Prices and Bid Affiliation: Evidence from Experimental Auctions", American Journal of Agricultural Economics, 88: 1078-1090.

Cox, J. and Grether, D. (1996), “The Preference Reversal Phenomenon: Response Mode, Markets and Incentives", Economic Theory, 7: 381-405.

Cubitt, R., Starmer, C. and Sugden, R. (2001), "Discovered Preferences and the Experimental Evidence of Violations of Expected Utility Theory", Journal of Economic Methodology, 8: $385-414$.

Cummings, R. and Taylor, L. (1999), "Unbiased Value Estimates for Environmental Goods: A Cheap Talk Design for the Contingent Valuation Method", American Economic Review, 89: 649-65.

Dasgupta, P. and Maskin, E. (2000), "Efficient Auctions”, Quarterly Journal of Economics, 115: $341-388$.

Dragicevic, A. and Ettinger, D. (2010), "Private Valuation of a Public Good in Three Auction Mechanisms”, CIRANO Working Paper 2010s-04. 
Einhorn, H. and Hogarth, R. (1985), "Ambiguity and Uncertainty in Probabilistic Inference", Psychological Review, 92: 433-461.

Forges, F. (1986), "Five Legitimate Definitions of Correlated Equilibrium in Games with Incomplete Information", Theory and Decision, 35: 277-310.

Forges, F. and Peck, J. (1995), "Correlated Equilibrium and Sunspot Equilibrium", Economic Theory, 5: 33-50.

Fox, J., Shogren, J., Hayes, D. and Kliebenstein, J. (1998), “CVM-X: Calibrating Contingent Values with Experimental Auction Markets", American Journal of Agricultural Economics, 80: 455-65.

Frensch, P. (1994), “Composition During Serial Learning: A Serial Position Effect”, Journal of Experimental Psychology, 80: 423-442.

Fudenberg, D. and Levine, D. (1998), “The Theory of Learning in Games”, MIT Press.

Gigerenzer, G. (1991), "Probabilistic Mental Models: a Brunswikian theory of Confidence", Psychological Review, 98: 506-528.

Gneezy, U. (2005), “Updating the Reference Level: Experimental Evidence”, in R. Zwick and A. Rapoport (eds), Experimental Business Research Volume III, Springer: 263-284.

Hanemann, M. (1994), "Valuing the Environment Through Contingent Valuation", Journal of Economic Perspectives, 8: 19-43.

Hardie, B, Johnson, E. and Fader, P. (1993), "Modeling Loss Aversion and Reference Dependence Effect on Brand Choice,” Marketing Science, 12: 378-394.

Hart, S. (2005), “Adaptive Heuristics”, Econometrica, 73: 1401-1430.

Hayes, D., Shogren, J., Shin, S. and Kliebenstein, J. (1995), "Valuing Food Safety in Experimental Auction Markets", American Journal of Agricultural Economics, 77: 40-53.

Helson, H. (1964), “Adaptation-Level Theory”, New York: Harper \& Row. 
Honkapohja, S. and Mitra, K. (2003), "Learning with Bounded Memory in Stochastic Models", Journal of Economic Dynamics and Control, 27: 1437-1457.

Horowitz, J. (2006), “The Becker-DeGroot-Marschak mechanism is not necessarily incentive compatible, even for non-random goods", Economics Letters, 93: 6-11.

Janiszewski, C. and Uy, D. (2008), "Precision of the Anchor Influences the Amount of Adjustment", Psychological Science, 19: 121-127.

Kagel, J. (1995), “Auctions: A Survey of Experimental Research.”, in J. Kagel and A. Roth (eds), Handbook of Experimental Economics, Princeton University Press: 501-585.

Kahneman, D., Knetsch, J. and Thaler, R. (1990), "Experimental Test of the Endowment Effect and the Coase Theorem", Journal of Political Economy, 98: 1325-1348.

Klemperer, P. (1999), "Auction Theory: A Guide to the Literature", Journal of Economic Surveys, 13: 227-286.

Knetsch, J., Tang, F. and Thaler, R. (2001), "The Endowment Effect and Repeated Market Rounds: Is the Vickrey Auction Demand Revealing?", Experimental Economics, 4: 257-69.

Koszegi, B. and Rabin, M. (2006), “A Model of Reference-Dependent Preferences”, Quarterly Journal of Economics, 121: 1133-1165.

Lawrence, M. and O'Connor, M. (1992), "Exploring Judgmental Forecasting", International Journal of Forecasting, 8: 15-26.

List, J. and Shogren, J. (1999), "Price Information and Bidding Behavior in Repeated SecondPrice Auctions?", American Journal of Agricultural Economics, 81: 942-949.

List, J. (2001), “Do Explicit Warnings Eliminate the Hypothetical Bias in Elicitation Procedures? Evidence from Field Auctions for Sportscards”, American Economic Review, 91: 1498-1507. 
Lusk, J., Daniel, M., Mark, D. and Lusk, C. (2001), "Alternative Calibration and Auction Institutions for Predicting Consumer Willingness to Pay of Nongenetically Modified Corn Chips", Journal of Agricultural and Resource Economics, 26: 40-57.

Lusk, J. and Shogren, J. (2007), "Incentive compatible auctions: theory and evidence", in Experimental Auctions, Methods and applications in Economic and Marketing Research, Cambridge University Press, 19-27.

Lusk, J., Alexander, C. and Rousu, M. (2007) "Designing Experimental Auctions for Marketing Research: The Effect of Values, Distributions, and Mechanisms on Incentives for Truthful Bidding”, Review of Marketing Science, 5: 1-30.

Manski, C. (2004), "Social Learning from Private Experiences: The Dynamics of the Selection Problem", Review of Economic Studies, 71: 443-458.

Myerson, R. (1983), “Mechanism Design by an Informed Principal”, Econometrica, 51: 17671797.

Milgrom, P. and Weber, R. (1982), "A Theory of Auctions and Competitive Bidding", Econometrica, 50: 1089-1122.

Northcraft, G. and Neale, M. (1987), "Experts, Amateurs, and Real Estate: An Anchoring-andAdjustment Perspective on Property Pricing Decisions", Organizational Behavior and Human Decision Processes, 39: 84-97.

Payne, J., Bettman J. and Johnson, E. (1988), “Adaptive Strategy Selection in Decision Making”, Journal of Experimental Psychology: Learning, Memory, and Cognition, 14: 534-552.

Plott, C. (1996), "Rational individual behavior in markets and social choice processes: the Discovered Preference Hypothesis", in Arrow, K., Colombatto, E., Perleman, M. and Schmidt, C., (eds.), Rational Foundations of Economic Behavior, Macmillan and St. Martins London, 225-250. 
Russo, J. and Schoemaker, P. (1989), “Decision Traps”, Doubleday Publishing Co.

Saran, R. and Serrano, R. (2007), "The Evolution of Bidding Behavior in Private-Values Auctions and Double Auctions", IMDEA Working Paper Series in Economics and Social Sciences, 2007/10.

Sela, A. and Herreiner, D. (1999), "Fictitious Play in Coordination Games", International Journal of Game Theory, 28: 189-197.

Shogren, J., Shin, S., Hayes, D. and Kliebenstein, J. (1994), "Resolving Differences in Willingness to Pay and Willingness to Accept”, American Economic Review, 84: 255-270.

Shogren, J. and Hayes, D. (1997), "Resolving Differences in Willingness to Pay and Willingness to Accept: Reply," American Economic Review, 87: 241-244.

Shogren, J., Margolis, M., Koo, C. and List, J. (2001), “A Random nth-price Auction”, Journal of Economic Behavior and Organization, 46: 409-421.

Slovic, P. and Lichtenstein, S. (1971), "Comparison of Bayesian and Regression Approaches to the Study of Information Processing in Judgment", Organizational Behavior and Human Decision Processes, 6: 649-744.

Spranca, M., Minsk, E. and Baron, J. (1991), “Omission and Commission in Judgment and Choice", Journal of Experimental Social Psychology, 27: 76-105.

Tversky, A. and Kahneman, D. (1974), “Judgment Under Uncertainty: Heuristics and Biases”, Science, 185: 1124-1130.

Tversky, A. and Kahneman, D. (1992), “Advances in Prospect Theory: Cumulative Representation of Uncertainty", Journal of Risk and Uncertainty, 5: 292-323.

Tversky, A. and Wakker, P. (1995), "Risk Attitudes and Decision Weights", Econometrica, 63: $1255-1280$. 
Van de Kuilen, G. (2009), "Subjective Probability Weighting and The Discovered Preference Hypothesis", Theory and Decision, 67: 1-22.

Weber, M. and Camerer, C. (1998), "The Disposition Effect in Securities Trading: An Experimental Analysis”, Journal of Economic Behavior and Organization, 33: 167-184. 


\section{TABLES}

Table 1 Summary statistics of the unbounded and bounded memory estimates

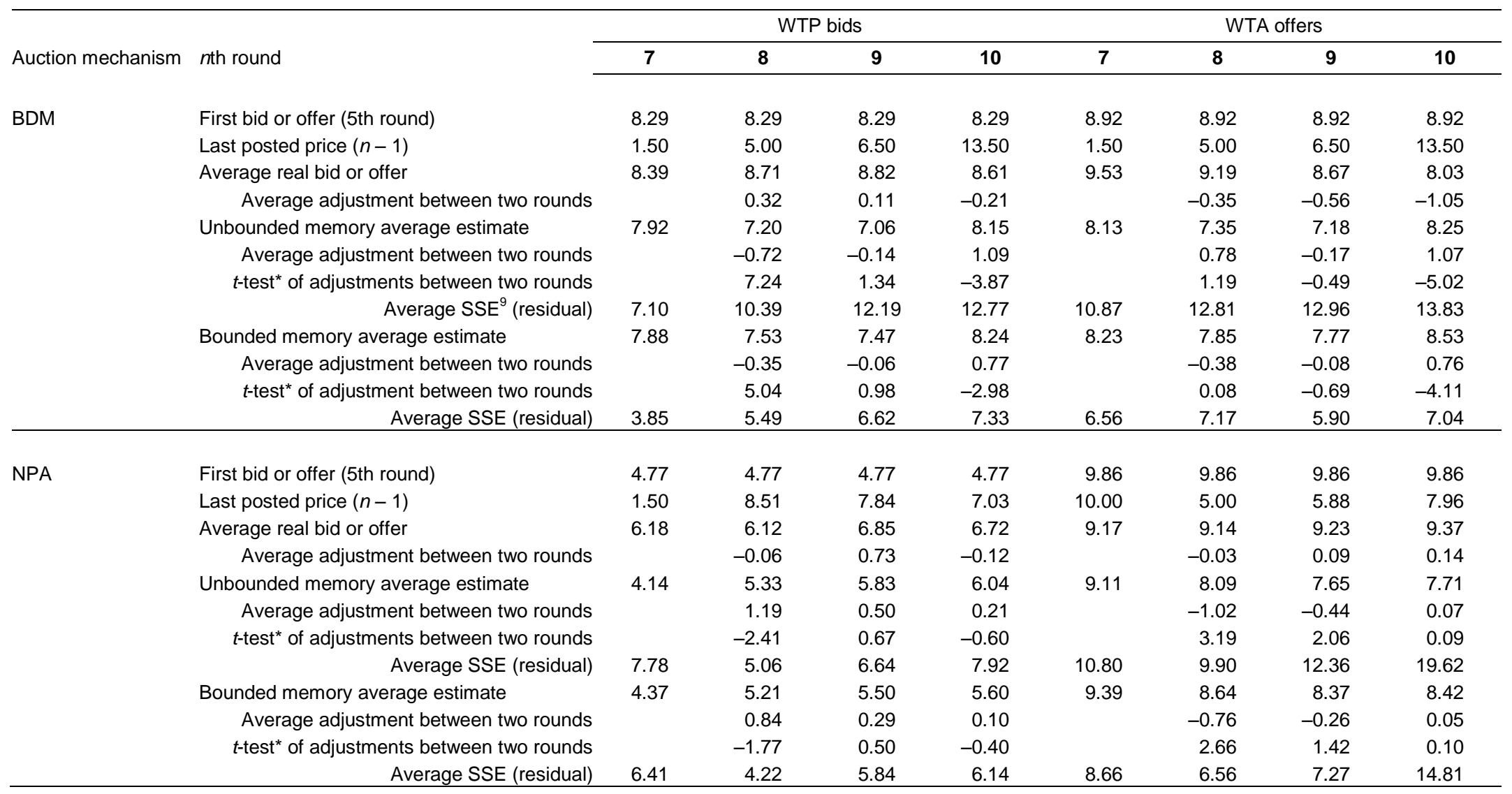

* $\mathrm{H}_{0}$ : The difference between experimental and theoretical average adjustments is zero at $5 \%$ significance.

${ }^{9}$ SSE: the sum of the squares of the residuals. 
Table $2 \gamma$-factors statistics

\begin{tabular}{lcccc}
\hline restimate $^{10}$ & \multicolumn{2}{c}{ Unbounded memory weighting } & \multicolumn{2}{c}{ Bounded memory weighting } \\
\hline BDM & NPA & BDM & NPA \\
\hline Bidders & $1.18(0.02)$ & $1.24(0.03)$ & $1.24(0.03)$ & $1.16(0.06)$ \\
Offerers & $1.19(0.02)$ & $1.17(0.03)$ & $1.15(0.03)$ & $1.21(0.07)$ \\
\hline
\end{tabular}

Table 3 Expected and real gainers from adjustment

\begin{tabular}{lcccc}
\hline per cent & BDM WTP & BDM WTA & NPA WTP & NPA WTA \\
\hline Expected gainers & 2.63 & 4.17 & 10.00 & 10.94 \\
Real gainers & 0.00 & 2.78 & 3.33 & 3.13 \\
\hline
\end{tabular}

Table 4 Expected and real gains from adjustment

\begin{tabular}{lcccc}
\hline on average & BDM WTP & BDM WTA & NPA WTP & NPA WTA \\
\hline Expected gain & 0.13 & -0.36 & 0.72 & 0.09 \\
Real gain & 0.13 & -0.22 & 0.26 & 0.08 \\
\hline
\end{tabular}

$\overline{{ }^{10} \text { Standard errors in parentheses. }}$ 


\section{FIGURES}



Figure 1 Bounded memory weighting

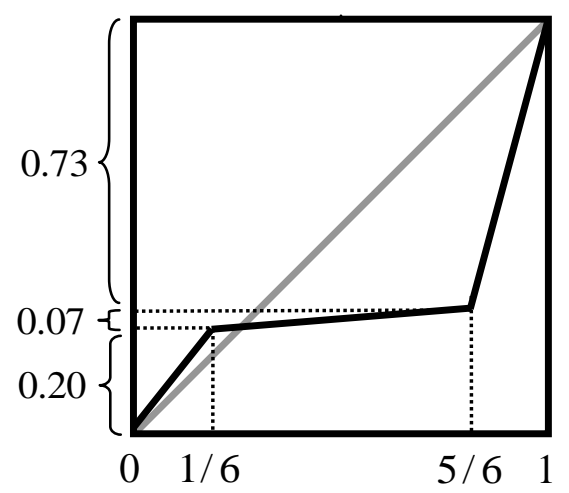

Figure 2 Average bounded memory weighting 